\title{
PELATIHAN PEMASARAN ONLINE PADA PELAKU USAHA KERIPIK TEMPE DAN KERIPIK BUAH DESA SUKOREJO KECAMATAN SIDAYU KABUPATEN GRESIK
}

\author{
Oleh: \\ Nurul Indawati ${ }^{1}$, Rosa Prafitri Juniarti², R.A. Sista Paramita ${ }^{3}$, Tias Andarini Indarwati ${ }^{4}$ \\ Jurusan Manajemen, Fakultas Ekonomi, Universitas Negeri Surabaya
}

\begin{abstract}
Abstrak
UMKM Desa Sukorejo memiliki beberapa produk unggulan yang tergabung dalam BUMDes Podhojoyo Sukorejo. Banyaknya produk yang dihasilkan oleh UMKM setempat, mendorong masyarakat dan pengelola BUMDes Podhojoyo Sukorejo untuk belajar terkait pemasaran online. Kegiatan PKM ini berupaya memberikan pelatihan dan pendampingan pemasaran online dengan materi pelatihan mengenai konsep komunikasi pemasaran dan pengenalan aplikasi pendukung pemasaran online (Shopee). Metode yang digunakan adalah pelatihan dan pendampingan serta monitoring evaluation agar proses pelaksanaan program PKM ini dapat berjalan sesuai rencana, memperoleh hasil sesuai harapan dan tuntas dilaksanakan. Hasil pelatihan dan pendampingan pemasaran online menunjukan bahwa peserta menjadi lebih mengetahui besarnya peluang pasar melalui toko online serta mengetahui proses memasarkan produk yang dimiliki pada toko online. Keberhasilan dan ketuntasan kegiatan ini tercermin dari dikelolanya akun toko online milik BUMDes Podhojoyo Sukorejo (shopee.co.id/bumdesasukerojo) hingga saat ini. Akun toko online milik BUMDes Podhojoyo Sukorejo tersebut telah melakukan aktivitas jual beli secara online terhitung sejak toko online pertama kali dibuat pada saat pelatihan dilaksanakan yaitu 2019 hingga 2021 ini.
\end{abstract}

Kata Kunci: pemasaran online, toko online, pelatihan dan pendampingan

\begin{abstract}
MSMEs Sukorejo have some excellent products incorporated in BUMDes Podhojoyo Sukorejo. The number of products produced by local MSMEs encourages the community and managers of BUMDes Podhojoyo Sukorejo to learn about online marketing. This PKM activity seeks to provide training and mentoring about online marketing with training materials on the concept of marketing communication and the introduction of online marketing applications (Shopee). The method used is training and mentoring as well as monitoring evaluation so that the process of implementing the PKM program can go according to plan, obtain results according to expectations and be carried out thoroughly. The results of online marketing training showed that participants became more aware of market opportunities through online stores. In addition, participants also know more about the process of marketing their products in online stores.
\end{abstract}

Keywords: online marketing, online stores, training and mentoring

\section{PENDAHULUAN}

UMKM di Desa Sukorejo sudah berkembang cukup bagus. Desa Sukorejo memiliki beberapa produk unggulan yang tergabung dalam BUMDes Podhojoyo Sukorejo. Dengan 50 produk unggulan yang tergabung dalam BUMDes maka kemampuan untuk memasarkan produk lebih luas menjadi kebutuhan dari UMKM di Desa Sukorejo. UMKM Sukorejo menghendaki adanya pelatihan dan pendampingan pemasaran online yang benar-benar memberikan dampak signifikan pada produk-produk yang dihasilkan oleh masyarakat setempat. Kebutuhan akan pemasaran online ini dapat $\begin{array}{lrc}\text { menjadi } & \text { strategi } & \text { untuk mengembangkan } \\ \text { UMKM } & \text { dalam rangka mendorong }\end{array}$ perekonomian di Indonesia. Pemasaran online (e-commerce) akan mendorong kinerja UMKM khususnya dari sisi finansial. Ketika ecommerce dijadikan sebagai alat bisnis secara optimal maka UMKM dapat menekan biaya operasional karena kegiatan promosi dan jual beli dilakukan secara online serta peningkatan pendapatan juga dapat terjadi karena pemasaran yang lebih luas sehingga memberikan potensi besar adanya pertumbuhan tingkat penjualan (Al-Alawi, A. \& Al-Ali, F (2015), Al-Hubail, A., (2014), Farida et., al., (2017), Kartiwi, Mira., et. al. (2018), Rita Rahayu dan John Day (2017), Wirdiyanti Rosnita (2019), Ueangkomsate 
(2015)). Disisilain, e-commerce juga memudahkan pembeli dalam mencari dan membeli barang yang diinginkan. Khan (2016), SachaOrloff Consulting Group (2012) mengungkapkan bahwa keunggulan utama ecommerce adalah efisiensi waktu yang signifikan ketika melakukan transaksi karena kemudahan akses untuk mencari barang dari seluruh dunia. Sehingga, PKM ini dilaksanakan dengan tujuan untuk memberikan pelatihan pemasaran online pada pelaku usaha di Desa Sidayu Kabupaten Gresik.

\section{METODE}

Metode pendekatan yang digunakan dalam Pengabdian Kepada Masyarakat berupa pelatihan terpadu. Pendekatan pelatihan yang diberikan diawali dengan pemberian materi mengenai komunikasi pemasaran online kemudian dilanjutkan dengan pendampingan pembuatan komunikasi pemasaran melalui media sosial. Progres mitra akan dimonitor untuk mengatasi permasalahan-permasalahan yang muncul pada mitra I dan mitra II.

Secara lebih spesifik kegiatan yang dilaksanakan adalah sebagai berikut.

\section{Pelatihan Komunikasi Pemasaran Online}

Pelatihan ini berisi tentang bagaimana mitra dapat membuat komunikasi pemasaran online yang sederhana, kreatif, dan efektif untuk mempersuasi audiens, mulai dari membuat iklan, membuat copywrite, memilih media, dan menentukan waktu yang tepat untuk mengomunikasikan iklan sosial media tersebut.

\section{Praktik dan Pendampingan Pembuatan Komunikasi Pemasaran Online}

Dalam praktik dan pendampingan ini, mitra diharapkan dapat membuat iklan, membuat copywrite, memilih media, dan menentukan waktu yang tepat untuk mengomunikasikan iklan sosial media tersebut dengan didampingi oleh tim PKM.

\section{Evaluasi}

Evaluasi dilakukan untuk mengetahui apakah komunikasi pemasaran yang dilakukan mendapatkan respon dari audiens. Respon tersebut dapat dilihat dari berapa view dan like yang muncul setelah iklan diposting.

\section{HASIL DAN PEMBAHASAN}

Pelatihan komunikasi pemasaran dibagi dalam 3 (Tiga) tahap. Tahap pertama yang dilakukan adalah mengomunikasikan dan menunjukan data pada para peserta bahwa pemasaran online memberikan peluang yang besar pada peningkatan penjualan produk peserta PKM. Salah satu toko online dengan jumlah pengunjung yang besar adalah toko online Shopee (jumlah pengunjung aplikasi Shopee kurang lebih 90 juta perbulan). Selain itu, Shopee juga menjadi toko online dengan rangking tertinggi di appstore dan playstore. Berdasarkan hal tersebut, maka Shopee dipilih menjadi toko online yang akan digunakan peserta untuk memasarkan produk mereka dalam PKM ini.

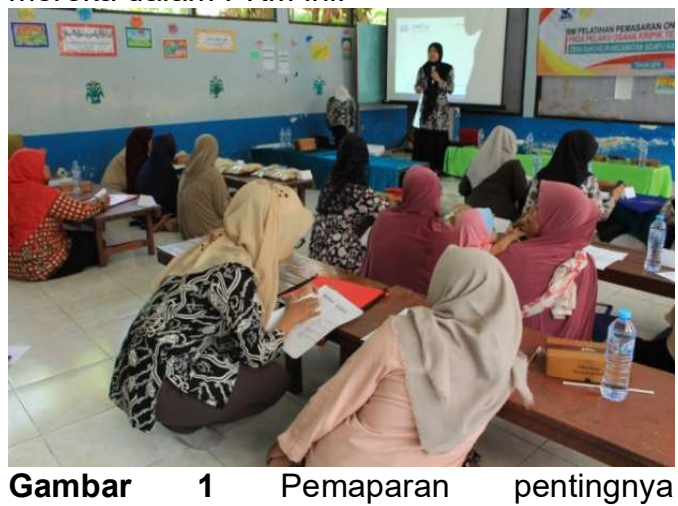

pemasaran online

Tahap kedua adalah mengajarkan pada peserta PKM proses pembuatan akun pada Shopee yang didahului dengan pembuatan email terlebih dahulu. Proses pembuatan email dilakukan didepan kelas dengan perwakilan salah satu peserta yang ingin dibuatkan email. Sedangkan peserta pelatihan yang lain mencoba membuat email melalui smartphone masing-masing. Setelah pembuatan email selesai, tahapan selanjutnya adalah pembuatan akun pada Shopee. Pembuatan akun toko online pada Shopee diwakili oleh BUMDes Podhojoyo Sukorejo, BUMDes Podhojoyo Sukorejo merupakan Badan Usaha Milik Desa Sukorejo yang menampung dan menjual seluruh produk yang dihasilkan oleh masyarakat Desa Sukorejo. Sehingga dengan membantu BUMDes Podhojoyo Sukorejo membuat toko online pada Shopee, maka diharapkan tingkat penjualan dan pangsa pasar dari setiap produk Desa Sukorejo juga semakin meningkat. 


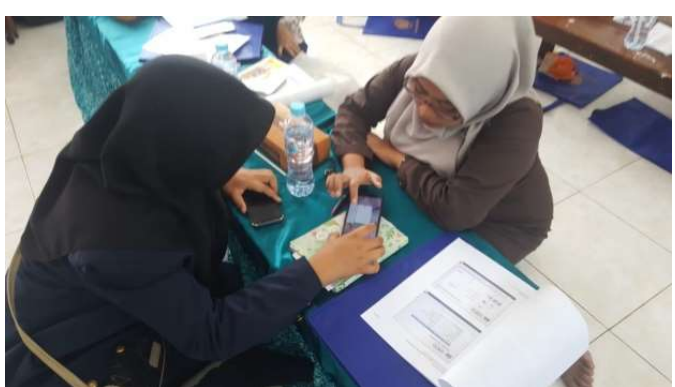

Gambar 2 Peserta dibimbing membuat akun toko online

Tahap ketiga adalah mengomunikasi produk melalui gambar dan komunikasi yang baik pada Shopee. Pada tahap ini, peserta pelatihan diajarkan cara mengambil gambar dengan baik. Sehingga kemasan produk yang sederhana dapat terlihat lebih menarik pada gambar. Teknik yang paling sederhana adalah dengan menunjukan kontras warna yang baik antara warna produk dengan warna background produk.
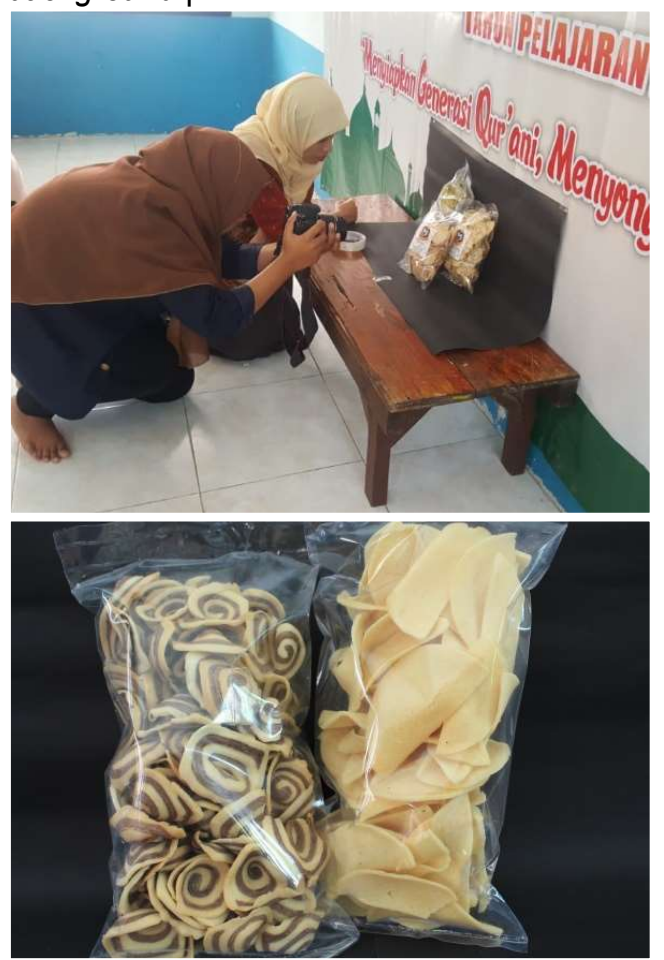

Gambar 3 Teknik pengambilan gambar produk

Pada tahap ketiga ini, BUMDes Podhojoyo Sukorejo dipilih menjadi peserta yang proses pembuatan toko onlinenya ditunjukan di depan kelas. Pembuatan toko online untuk BUMDes Podhojoyo Sukorejo dimulai dari pembuatan email dan kemudian mendaftarkan email tersebut pada toko online Shopee. Setelah toko online untuk BUMDes Podhojoyo Sukorejo terbuat, maka proses selanjutnya adalah menampilkan gambargambar produk Desa Sukorejo yang akan dijual secara online.

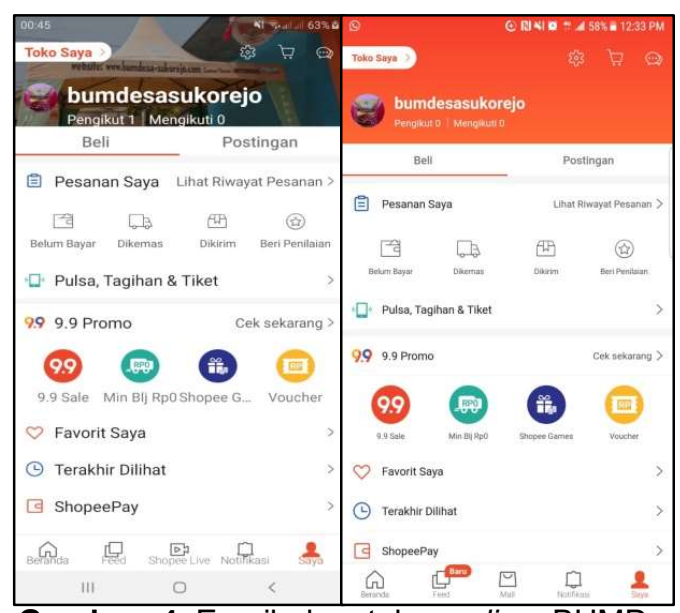

Gambar 4 Email dan toko online BUMDes Podhojoyo Sukorejo

Tahap ketiga dilanjutkan hingga praktik jual beli online dipraktikan. Setelah produk muncul pada akun toko online BUMDes Podhojoyo Sukorejo, salah satu anggota TIM PKM mencoba membeli produk tersebut secara online melalui akun Shopee yang dimiliki. Praktik proses jual beli berlanjut hingga pembeli memilih produk dan membayar produk yang telah dipilih dan dilanjutkan oleh pihak BUMDes Podhojoyo Sukorejo yang berhasil menerima pesanan dan memperoleh konfirmasi pembayaran terkait produk yang dipesan. Praktik jual beli selesai ketika paket produk berhasil sampai pada pembeli pada tanggal 7 September 2019.

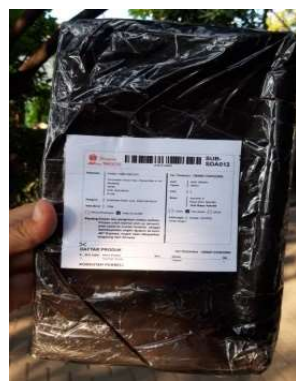

Gambar 5 Paket BUMDes Podhojoyo Sukorejo telah diterima Pembeli

Keunggulan dan kelemahan luaran keunggulan dari kegiatan ini adalah 
kesesuaian antara pelatihan yang diberikan dengan kebutuhan UMKM di Desa Sukorejo. Pelaku usaha Desa Sukorejo menghendaki adanya pelatihan pemasaran online dan kegiatan PKM ini dapat mewadahi kebutuhan tersebut. Kelemahan dari kegiatan ini adalah aktivitas mitra pada beberapa pekerjaan menjadi penghambat aktivitas pada pemesaran online.

Tingkat kesulitan pelaksanaan kegiatan Salah satu kesulitan pelaksanaan pelatihan pemasaran online ini adalah beberapa pelaku usaha yang baru mengetahui pengoperasian toko online. Kesulitan ini dapat diatasi dengan melakukan pendampingan pada individu yang mengalami kesulitan proses pembukaan toko online. Kesulitan kedua adalah tidak semua pelaku usaha didukung oleh media yang dapat mengakses toko online. Solusi untuk kesulitan ini adalah memfokuskan kegiatan pembukaan toko online pada BUMDes Podhojoyo Sukorejo sehingga setiap produk masyarakat Desa Sukorejo yang berada pada BUMDes akan dipasarkan secara online malalui akun toko online BUMDes Podhojoyo Sukorejo.

Tabel 1. Hasil Pretest dan posttest peserta pelatihan pemasaran online

\begin{tabular}{|c|l|c|c|c|c|c|c|}
\hline \multirow{2}{*}{ No. } & \multirow{2}{*}{ Nama Peserta } & \multicolumn{3}{|c|}{ Pretest } & \multicolumn{3}{c|}{ Post Test } \\
\cline { 3 - 7 } & & Salah & Betul & Nilai & Salah & Betul & Nilai \\
\hline 1 & Rhohimah Ikhsan & 3 & 9 & 74,7 & 1 & 11 & 91,3 \\
\hline 2 & Khoirotun Masuchah & 1 & 11 & 91,3 & 0 & 12 & 99,6 \\
\hline 3 & Eliska Findy Selvia & 2 & 10 & 83 & 0 & 12 & 99,6 \\
\hline 4 & Masfiroh & 6 & 6 & 49,8 & 2 & 10 & 83 \\
\hline 5 & Uliamah & 3 & 9 & 74,7 & 1 & 11 & 91,3 \\
\hline 6 & Sutatik & 3 & 9 & 74,7 & 1 & 11 & 91,3 \\
\hline 7 & Kurniawati & 3 & 9 & 74,7 & 1 & 11 & 91,3 \\
\hline 8 & Herlik Kusmawati & 2 & 10 & 83 & 0 & 12 & 99,6 \\
\hline 9 & Setya Ningsih & 3 & 9 & 74,7 & 1 & 11 & 91,3 \\
\hline 10 & Nur Aini & 5 & 7 & 58,1 & 2 & 10 & 83 \\
\hline 11 & Sarijem & 2 & 10 & 83 & 0 & 12 & 99,6 \\
\hline 12 & Reni Ayu Wulandari & 2 & 10 & 83 & 0 & 12 & 99,6 \\
\hline 13 & Nur Indayati & 2 & 10 & 83 & 0 & 12 & 99,6 \\
\hline 14 & Luluk Anita & 3 & 9 & 74,7 & 1 & 11 & 91,3 \\
\hline
\end{tabular}

Hasil pretest dan posttest dari masing-masing peserta menunjukan bahwa setelah mengikuti pelatihan pemasaran online peserta menjadi lebih paham terkait pasar online dan bagaimana cara memposting produk pada toko online. Hasil pretest dan posttest ditunjukan pada tabel berikut.

\section{SIMPULAN DAN SARAN}

\section{Simpulan}

- PKM ini telah memenuhi seluruh target, yaitu memberikan pelatihan dan pendampingan terkait komunikasi online, memberikan paduan, menyusun laporan akhir, dan menyusun artikel.

- PKM pemasaran online yang diberikan pada pelaku usaha Desa Sukorejo sesuai dengan kebutuhan pelaku usaha Desa Sukorejo.

- Manfaat yang diperoleh melalui pelatihan dan pendampingan pemasaran online adalah masyarakat/ pelaku usaha Desa
Sukorejo jadi lebih mengetahui besarnya peluang pada pemasaran online, mengetahui proses/ tahapan membuka toko online, dan mengetahui praktik jual beli online. Sehingga setelah pelatihan pemasaran online diharapkan seluruh pelaku usaha khususnya BUMDes Podhojoyo Sukorejo dapat lebih aktif dalam kegiatan pemasaran online.

\section{Saran}

Kegiatan PKM pada Desa Sukorejo berikutnya agar dapat lebih berfokus pada pendampingan pemasaran online. Karena banyaknya kegiatan para pelaku usaha 
ditambah kurang berkesinambungnya pendampingan akan memunculkan peluang kurang aktifnya peserta dalam mengelola toko online yang dimiliki.

\section{DAFTAR PUSTAKA}

Al-Alawi, A. \& Al-Ali, F., (2015) 'Factors Affecting Ecommerce Adoption in SMEs in the GCC: An Empirical study of Kuwait', Research Journal of Information Technology, 7(1): 1-21.

Al-Hubail, A., (2014) ' Impact of E-commerce on the Financial Performance of SME's in Saudi Arabia' , A Dissertation Submitted in Partial Fulfilment of the Degree of MSc in Financial Management, Middlesex University, London, UK.

Amir Sedighi and Behroz Sirang. 2018. The Effect of E-Commerce on SME Performance. International Journal of Applied Research in Management and Economics.

Farida, N., Naryoso, A \& Yuniawan, A. 2017. Model of Relationship Marketing and E-Commerce in Improving Marketing Performance of Batik SMEs. Jurnal Dinamika Manajemen. 8 (1): 20-29.

Kartiwi et al. 2018. Impact of external factors on determining E-commerce benefits among SMEs in Malaysia. Journal of Global Entrepreneurship Research (2018) 8:18.

Katz, Bernardt 1994. Komunikasi Bisnis. Cetakan Pertama, Jakarta: Penerbit Ikrar Mandiri Abadi.
Khan, A. G. 2016. Electronic Commerce: a Study on Benefits and Challenges in An Emerging Economy. Global Journal of Management and Business Research. 16 (1): 18-22.

Rahayu, Rita and John Day. 2017. Ecommerce adoption by SMEs in developing countries: evidence from Indonesia. Eurasian Bus Rev 7:2541

SachaOrloff Consulting Group. (2012), Ecommerce in Saudi Arabia: Driving the evolution, adaption and growth of e-commerce in the retail industry.

Ueangkomsate, P. 2015. Adoption ECommerce for Export Market of Small and Medium Enterprise in Thailand. Procedia-social and Behavioral Sciences. 207: 111-120.

\section{Sumber elektronik :}

Dinas Komunikasi dan Informatika Kab. Gresik. Desa Sukorejo. https://sidesa.gresikkab.go.id/desa-sukorejosidayu/ . diakses pada 28 Mei 2021 